\title{
Aquatic macroinvertebrate responses to native and non-native predators
}

\author{
N.R. Haddaway ${ }^{(1),(2), \star}$, D. Vieille ${ }^{(3)}$, R.J.G. Mortimer ${ }^{(4)}$, M. Christmas ${ }^{(5)}$, \\ A.M. Dunn ${ }^{(2)}$
}

Received September 14, 2014

Revised November 12, 2014

Accepted November 15, 2014

\section{ABSTRACT}

Key-words: antipredator behaviour, non-native, invasive, Austropotamobius gus jenkinsi, to olfactory cues from three predators: sympatric native fish pallipes, Pacifastacus leniusculus, alien, community ecology

Non-native species can profoundly affect native ecosystems through trophic interactions with native species. Native prey may respond differently to non-native versus native predators since they lack prior experience. Here we investigate antipredator responses of two common freshwater macroinvertebrates, Gammarus pulex and Potamopyr(Gasterosteus aculeatus), sympatric native crayfish (Austropotamobius pallipes), and novel invasive crayfish (Pacifastacus leniusculus). G. pulex responded differently to fish and crayfish; showing enhanced locomotion in response to fish, but a preference for the dark over the light in response to the crayfish. $P$. jenkinsi showed increased vertical migration in response to all three predator cues relative to controls. These different responses to fish and crayfish are hypothesised to reflect the predators' differing predation types; benthic for crayfish and pelagic for fish. However, we found no difference in response to native versus invasive crayfish, indicating that prey naivete is unlikely to drive the impacts of invasive crayfish. The Predator Recognition Continuum Hypothesis proposes that benefits of generalisable predator recognition outweigh costs when predators are diverse. Generalised responses of prey as observed here will be adaptive in the presence of an invader, and may reduce novel predators' potential impacts.

RÉSUMÉ

Réponses de macro-invertébrés aquatiques aux prédateurs indigènes et non indigènes

\begin{abstract}
Mots-clés : comportement antiprédateur, non-native, invasive,

Les espèces non indigènes peuvent affecter profondément les écosystèmes par des interactions trophiques avec des espèces indigènes. Les proies indigènes peuvent réagir différemment aux prédateurs indigènes ou non indigènes, car elles manquent d'expérience préalable. Nous étudions ici les réponses antiprédatrices de deux macro-invertébrés d'eau douce communs, Gammarus pulex et Potamopyrgus jenkinsi, aux signaux olfactifs de trois prédateurs; poisson sympatrique natif (Gasterosteus aculeatus), l'écrevisse indigène sympatrique (Austropotamobius pallipes), et une nouvelle écrevisse invasive (Pacifastacus leniusculus).
\end{abstract}

(1) Centre for Evidence-Based Conservation, Bangor University, Bangor, LL57 2UW, UK

(2) School of Biology, University of Leeds, LS2 9JT, UK

(3) DREAL (Direction Régionale de l'Environnement, de l'Aménagement et du Logement), 21 Boulevard Voltaire, 21000 Dijon, France

(4) School of Earth and Environment, University of Leeds, Leeds, LS2 9JT, UK

(5) Environment Agency, Rivers House, 21 Park Square South, Leeds, West Yorkshire, LS1 2QG, UK

*Corresponding author: neal_haddaway@hotmail.com 
Austropotamobius G. pulex ont réagi différemment aux poissons et aux écrevisses; montrant une pallipes, Pacifastacus leniusculus, alien, écologie des communautés locomotion accrue en réponse aux poissons, mais une préférence pour le noir sur la lumière en réponse à l'écrevisse. $P$. jenkinsi ont montré une augmentation des migrations verticales en réponse à tous les trois signaux des prédateurs par rapport aux témoins. Ces différentes réponses aux poissons et écrevisses sont supposées refléter les différents types de prédation des prédateurs; benthique pour les écrevisses et pélagiques pour les poissons. Cependant, nous n'avons trouvé aucune différence en réponse aux écrevisses invasives ou natives, ce qui indique que la naïveté de la proie n'intervient pas dans les impacts de l'écrevisse invasive. L'hypothèse du Continuum de Reconnaissance du Prédateur propose que les avantages de la reconnaissance générique du prédateur l'emportent sur les coûts lorsque les prédateurs sont divers. Les réponses des proies comme observées ici seront adaptatives en présence d'un envahisseur, et peuvent réduire les impacts potentiels de nouveaux prédateurs.

\section{INTRODUCTION}

Adaptive changes in life history, morphology, and behaviour in response to predator pressure (e.g. DeWitt and Scheiner, 2004) are generally costly in terms of a reduction in growth, survival and reproduction (Auld et al., 2010; Trussell and Nicklin, 2002). 'Inducible defences' are adaptive as they allow prey to employ potentially costly predator avoidance strategies only in the presence of a predator (Turner, 2008). The reliability of environmental cues is important for the evolution of stable inducible defences (Harvell and Tollrian, 1999; Reed et al., 2010).

Environmental cues experienced during development may be important for antipredator responses (Dalesman et al., 2009), particularly in freshwater systems (see Brönmark and Hansson, 2007), but in some instances, antipredator responses may be innate (reviewed by Mery and Burns, 2010). Ferrari et al. (2007) refer to this continuum between innate responses and generalised learnt responses as the Predator Recognition Continuum Hypothesis. The Predator Recognition Continuum Hypothesis suggests that generalising antipredator responses to novel potential predators is beneficial when the number of different predator species is high, and that innate, fixed responses are preferential when the number of predators is low (Ferrari et al., 2007). This results from a high degree of predictability in prey responses where only a small number of predator species are encountered. Alternatively, where a large number of different predators may be encountered, flexibility in responses is preferable to innate antipredator behaviours.

Invasive, non-native species are major drivers of biodiversity loss and changes in community structure in freshwater ecosystems (Vitousek et al., 1996; McGeoch et al., 2010). Many problems associated with animal invasive alien species arise from their predatory/consumptive impacts on native species (e.g. Albins and Hixon, 2013). Predatory invaders may affect prey densities and may also drive altered behaviour, life history, and morphology, with potential ramifications throughout the ecosystem (reviewed in Simberloff, 2011). In many cases, invasive predators have greater impact on prey than do native predator species (Haddaway et al., 2012). The predatory impact of non-native invasive species may be a result of novel predation strategies of non-native species that differ from those of native predators, or may be because native species of prey cannot recognise non-native species nor respond to them with appropriate predator-avoidance mechanisms (reviewed in Sih and McCarthy, 2002). Indigenous species possess a repertoire of adaptive defences to local pathogens, parasites, competitors, predators and/or herbivores as a result of ecological interactions over the course of evolution, but depending on the specificity of the defensive trait, such defences may not be useful against newly introduced species.

Invasion by the American signal crayfish, Pacifastacus leniusculus, in Europe is associated with environmental changes, including habitat degradation (Harvey et al., 2011) and reductions in native macroinvertebrate diversity (e.g. Jackson et al., 2014). The invasive crayfish has 
stronger predatory impact than the native species Austropotamobiu pallipes on several native prey species that has been shown to result from differences in prey choice and predatory functional response (Haddaway et al., 2012), leading to the prediction that native prey show lower antipredator defences to the invasive crayfish predator. Here we examine the antipredator responses of two highly abundant macroinvertebrates (the amphipod Gammarus pulex and the gastropod Potamopyrgus jenkinsi) in UK rivers to three predators: a native fish (the stickleback Gasterosteus aculeatus), a native crayfish (the white-clawed crayfish $A$. pallipes), and an invasive non-native crayfish (the North American crayfish Pacifastacus leniusculus). We test the hypothesis that prey should show a greater response to the native crayfish than to the invader. We also compare prey responses to crayfish and fish predators with different predatory strategies; crayfish are nocturnal sit-and-wait predators (Gherardi et al., 2001); whereas the stickleback is a diurnal visual forager (Svenster et al., 1995).

\section{METHODS}

\section{> PREY COLLECTION AND STORAGE}

G. pulex were collected by kick-sampling from Meanwood Beck (NGR: SE279372, Lat/Long: 53.830319/1.577584) and P. jenkinsi were collected from Wyke Beck, UK (NGR: SE341363, Lat/Long: 53.821861/1.483487) in March 2010. Both sites are inhabited by the native crayfish (A. pallipes) and the native fish predator (G. aculeatus). Animals were naïve to the invasive crayfish ( $P$. leniusculus). All animals were maintained at the University of Leeds at 17 degrees $\mathrm{C}$ on a fixed light:dark cycle of 17L:7D and were fed ab libitum on rotting birch leaves. Experiments were all undertaken in March 2010 during daylight. Prey animals were used as natural food for crayfish following the experiments.

\section{>PREDATOR COLLECTION AND STORAGE}

Predators were collected using a combination of stone-turning and trap-setting for crayfish, and a D-net for fish from the following sites under relevant licenses (Environment Agency/Natural England/CEFAS); G. aculeatus from/to Saltfleet in Lincolnshire (NGR: TF453939, Lat/Long: 53.421887/0.185085), A. pallipes from/to Wkye Beck (described above), and P. leniusculus from Baylis Pools in Shropshire (NGR: SJ733088, Lat/Long: 52.676239/2.396330). Predators were maintained in constant environmental conditions (as for prey, above) at the University of Leeds for two weeks prior to cue production. Predators were fed daily on a mixture of frozen bloodworm and specialist crustacean dried pellets produced from white fish meal (Hikari Tropical Crab Cuisine ${ }^{\circledR}$ ). All predators were fed the same food, with excess removed regularly to avoid fouling of the water. Predators were returned to their respective sources immediately following the experiments (with the exception of $P$. leniusculus). $P$. leniusculus were not released but held for further study, in agreement with UK legislation regarding invasive species.

\section{> EXPERIMENTAL DESIGN}

\section{Cues}

Aquatic macroinvertebrates show antipredator responses to various cues (Dicke and Grostal, 2001). However, aquatic environments are often characterised by reduced visibility and chemoreception is the major method of environmental sensing (Nyström and Åbjörnsson, 2000). Olfactory cues detected by prey may arise from predator kairomones (that benefit the receiver but not the transmitter) or alarm signals (transmitted between conspecifics) (reviewed by Chivers and Smith, 1998). In order to focus on differences in prey response between predators we used only predator kairomones and not alarm signals. Previous research has shown 
that prey can respond to olfactory cues from feeding fish irrespective of diet (conspecific versus other prey) (Paterson et al., 2013), and so feeding cues may conflate alarm signals with kairomones. Future research may benefit from including feeding predator olfactory cues to investigate these collective impacts of kairomones and alarm signals.

Olfactory predator cues were produced using water taken from tanks containing one of three predator species (each observed to predate all prey species in preliminary trials); native fish (the three-spined stickleback G. aculeatus), invasive crayfish (the North American signal crayfish $P$. leniusculus), and native crayfish (the white-clawed crayfish $A$. pallipes). Individual sizematched (c. $80 \mathrm{~mm}$ total length) predators were maintained, unfed, in separate plastic tanks filled with $1.6 \mathrm{I}$ of dechlorinated tap water with one $5 \mathrm{~cm}$ pipe for shelter for a period of $24 \mathrm{~h}$. Cues were produced from a total of three individual predators of each species, and individuals' cues were randomised across replicates throughout the experiment. Predators were exchanged every three days during trials. A control cue was produced using dechlorinated tap water.

\section{Experimental procedure}

For G. pulex, we investigated light/dark preferences (e.g. Bethel and Holmes, 1973) and developed a new protocol for an experiment to measure locomotory responses to predator cues. For $P$. jenkinsi we measured vertical migration in response to predator cues (e.g. Turner, 1996).

\section{Experiment 1 - Locomotory response in G. pulex}

In this experiment G. pulex were tested for antipredator responses in the form of changes in locomotion pattern. In order to track movement, a silt suspension was made using filtered $(0.1 \mathrm{~mm}$ mesh) mud from the field site. The suspension (c. $500 \mathrm{ml})$ was added to a white tray $(417 \times 315 \mathrm{~mm})$ along with $30 \mathrm{ml}$ of predator or control cue, mixed thoroughly and then allowed to settle for $2 \mathrm{~min}$. Individual G. pulex were placed in the centre of the tray and the path of the test animal was followed by photographing the trail it produced in the silt over $180 \mathrm{~s}$. Thirty individual prey were used, with each individual being used a total of four times, once for each predator cue, with individuals assigned to random predator cue sequences. Whilst this is not as preferable as using different individuals, they were exposed to cues on four separate days with two rest days between cues to allow baseline behaviours to re-establish between treatments, and treatments were assigned randomly across time to each prey. Individual animals were maintained in dechlorinated tap water. Shelter and food was provided in the form of washed rotting sycamore leaves (1 leaf per container).

TPS Dig2 (Rohlf, 1997) software was employed to place landmarks on digital images where a substantial change of direction ( $>20$ degrees) occurred. Sketches of track direction were used to order landmarks correctly. In this way the number of changes of direction, individual distances travelled and total distance travelled were recorded.

\section{Experiment 2 - Light/Dark choice in G. pulex}

To compare light/dark choices in the different predator treatments, a circular transparent plastic pot $(80 \mathrm{~mm}$ diameter) was filled to a depth of $20 \mathrm{~mm}$ with dechlorinated water (c. $100 \mathrm{ml}$ ) and $30 \mathrm{ml}$ of predator cue. One half of the pot was covered in black plastic and a single light source was placed directly above the pot to create a shadowed "dark side" and a "light side". Individual G. pulex were placed in the centre of the pot, and over $180 \mathrm{~s}$ the time spent in the dark was recorded. Treatments (30 replicates per treatment) were randomised over time and the pot was rotated by 180 degrees between each trial. Trials were carried out on four separate days with two non-experimental days between cues to allow baseline behaviours to re-establish. 


\section{Experiment 3 - Vertical migration in P. jenkinsi}

In this experiment, the snail $P$. jenkinsi was tested for antipredator response in the form of vertical migration and floating. Small plastic containers measuring $80 \mathrm{~mm}$ in diameter were filled to a depth of $40 \mathrm{~mm}$ (c. $100 \mathrm{ml}$ ) with dechlorinated water and $30 \mathrm{ml}$ of predator cue. In each replicate, twenty individual $P$. jenkinsi were placed on the centre of the base of the pot. After $3 \mathrm{~h}$ the number of snails in each of four location positions was recorded. The positions were: "base" (remaining in the centre on the base), "climbing" (between the substrate and the surface), "surface" (at or above the surface in contact with the sides), or "floating" (at the surface and not in contact with the sides). Thirty replicates (each replicate containing 20 snails) were used per treatment and each group of snails was used once for each treatment (four times in total; order of treatments randomised). Experiments were run in a total of four days, with six replicates run per day. Two rest days were used between trials to allow for re-establishment of baseline behaviour. Pots were randomised spatially.

\section{> STATISTICAL ANALYSIS}

All analyses were performed using $R$ (R Development Core Team, 2005). In all cases where significant differences between predator cues were detected, pairwise comparisons were performed without adjustment of $p$-values. Instead, Bonferroni adjustment of alpha (typically $\alpha=0.05$ ) based on the number of pairwise comparisons was employed for clarity.

The number of changes of direction and total distance travelled by G. pulex were compared between treatments using linear mixed effects models with individual prey identity as a random effect, since residuals were normally distributed (distance travelled (Shapiro-Wilk: $W=0.992, p=0.583$ ), changes in direction (Shapiro-Wilk: $W=0.988, p=0.228)$ ). All variances were homogeneous $(p<0.05)$. Time spent in the dark was compared between predator cues for G. pulex using a linear mixed effects model (LME) using individual prey identity as a random effect. Pairwise comparisons were undertaken using similar linear mixed effects models. A principal components analysis (PCA) was performed on position data from experiments with $P$. jenkinsi and used to produce three principal components. The first and second principal components were tested against treatment with linear mixed effects model (LME (Pinheiro and Bates, 2000)) with the random effect being the snail group used.

\section{RESULTS}

\section{> EXPERIMENT 1 - LOCOMOTORY RESPONSE IN G. PULEX}

We found that total distance travelled by G. pulex differed significantly between predator cues (LME: $F_{3,109}=7.055, p<0.001$ ) (Figure 1, Table I). G. pulex travelled further in the presence of the invasive crayfish than in controls or in the presence of native fish. There was no significant difference in distance travelled in response to native versus invasive crayfish. Native fish cues elicited no detectable change in comparison with controls and all other pairwise comparisons were not significant $(p>0.008$; threshold of significant, $\alpha$, conservatively reduced to account for multiplicity of $p$-values in pairwise comparisons). We found the number of changes of direction by $G$. pulex to be unaffected by predator cue (LME: $F_{3,109}=2.450, p=0.070$ ).

\section{> EXPERIMENT 2 - LIGHTIDARK CHOICE IN G. PULEX}

We found that time spent by G. pulex in the dark relative to the light differed significantly between predator cues (LME: $F_{3,115}=17.408, p<0.001$ ) (Figure 2, Table II). G. pulex showed no difference in phototactic behaviour in response to cues from native or invasive crayfish in comparison with the control, whereas prey spent significantly more time in the dark in response to the native fish relative to controls, invasive crayfish and native crayfish. 


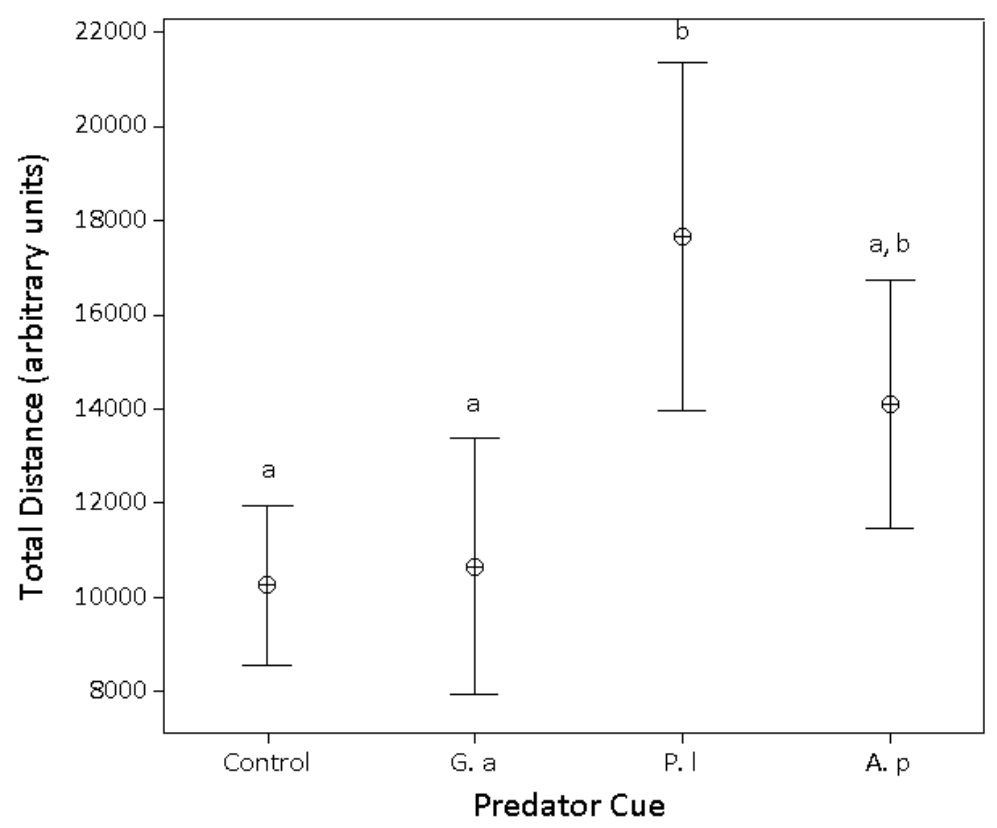

Figure 1

Total distance travelled over 180 seconds for Gammarus pulex presented with different predator cues; "Control" - no predator cue, "Native fish" - Gasterosteus aculeatus, "Non-native crayfish" - Pacifastacus leniusculus, "Native crayfish" Austropotamobius pallipes. Points are means and bars are \pm two standard errors. Lines above indicate significant pairwise differences at Bonferoni adjusted $\alpha=0.008$.

\section{Table I}

Pairwise comparisons for linear mixed effects model of total distance travelled in G. pulex locomotory response experiment. Degrees of freedom for all pairwise comparisons $=1,56$. *denotes statistical significance relative to a Bonferonni-adjusted level of alpha, $\alpha=0.008$.

\begin{tabular}{|l|c|c|c|c|}
\cline { 2 - 5 } \multicolumn{1}{c|}{} & Control & Native fish & Native crayfish & Invasive crayfish \\
\hline Control & - & $F=0.076$ & $F=5.599$ & $F=14.315$ \\
& & $p=0.784$ & $P=0.021$ & $P<0.001^{*}$ \\
\hline Native fish & & - & $F=4.672$ & $F=10.933$ \\
& & & $P=0.040$ & $P=0.003^{*}$ \\
\hline Native crayfish & & & - & $F=2.608$ \\
& & & & $P=0.119$ \\
\hline Invasive crayfish & & & & - \\
\hline
\end{tabular}

\section{> EXPERIMENT 3 - VERTICAL MIGRATION IN P. JENKINSI}

Two grouping variables were identified in the PCA for the vertical migration results; relocated (all responses where snails had moved from the bottom of the arena; climbing, at or above the surface, or floating) and static (snails remained on the bottom of the arena). This relocated-vsstatic variable was the main factor structuring variability along the first principal component. Although we use the terms relocated and static it is possible that the "static" snails had moved but returned to the base of the pot. The relocated-vs.-static variable accounted for substantial variation in the data (eigenvalue $=2.498,62.4$ percent of total variation). Table III shows the magnitude and direction of the contribution of each variable to this first principal component. Distinct differences between the three predator cues and the control along this axis are evident in Figure 3 (LME: $\left.F_{3,115}=13.994, p<0.001\right)$, showing that snails responded significantly to all predators but failed to leave the base in controls. Native and invasive crayfish cues are grouped centrally around zero, corresponding to equal degrees of static and relocated behaviours (mean snail number of 8.0 relocated and 12.0 static for both native and invasive crayfish). Native fish cues are clustered high on the axis, corresponding to high levels of relocated behaviours, with snails responding greatest to native fish, then 


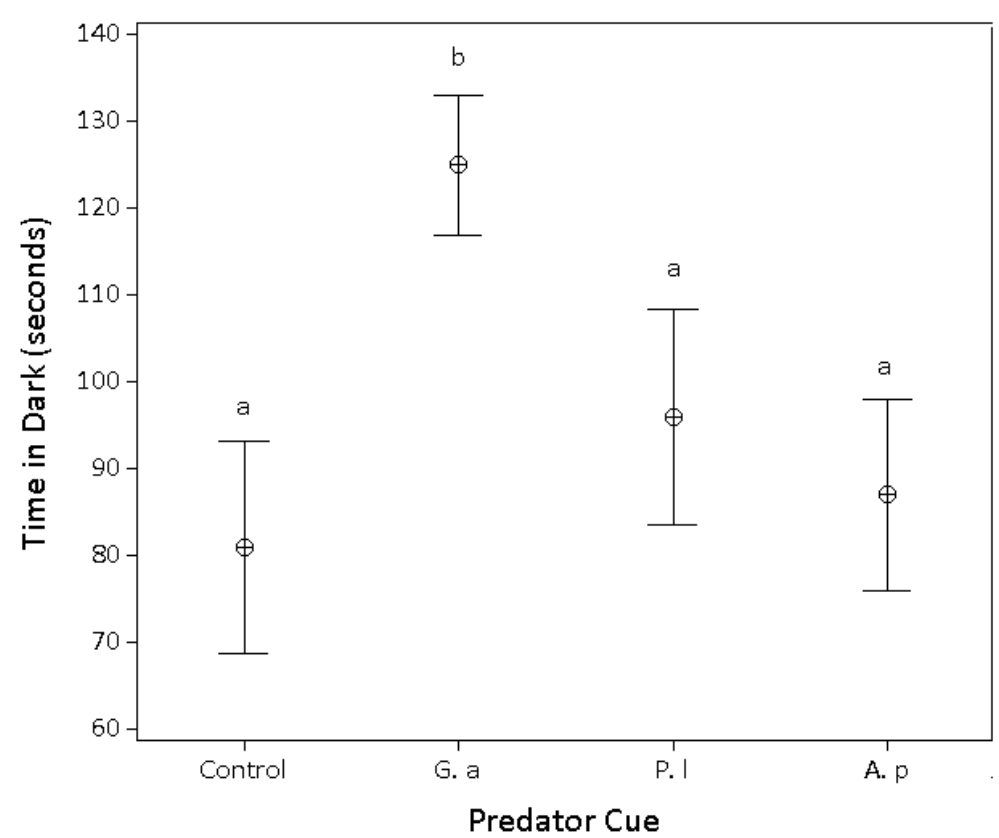

\section{Figure 2}

Time spent in dark for Gammarus pulex presented with different predator cues; "Control" - no predator cue, "Native fish" - Gasterosteus aculeatus, "Non-native crayfish" - Pacifastacus leniusculus, "Native crayfish" Austropotamobius pallipes. Points are means and bars are \pm two standard errors. Lines above indicate significant pairwise differences at Bonferoni adjusted $\alpha=0.008$.

\section{Table II}

Pairwise comparisons for linear mixed effects model of time spent in the light in G. pulex light/dark response experiment. Degrees of freedom for all pairwise comparisons $=1.56$. *denotes statistical significance relative to a Bonferonni-adjusted level of alpha, $\alpha=0.008$.

\begin{tabular}{|l|c|c|c|c|}
\cline { 2 - 5 } \multicolumn{1}{c|}{} & Control & Native fish & Native crayfish & Invasive crayfish \\
\hline Control & - & $F=53.787$ & $F=0.594$ & $F=5.520$ \\
& & $P<0.001^{*}$ & $P=0.447$ & $P=0.026$ \\
\hline Native fish & & - & $F=36.776$ & $F=21.708$ \\
& & & $P<0.001^{*}$ & $P<0.001^{*}$ \\
\hline Native crayfish & & & - & $F=1.786$ \\
& & & & $P=0.192$ \\
\hline Invasive crayfish & & & & - \\
\hline
\end{tabular}

\section{Table III}

Contributions of activity measures towards the first principal component (PC1) of a PCA for Potamopyrgus jenkinsi following exposure to predator cues.

\begin{tabular}{|l|c|}
\hline Activity Measure & Contribution to PC1 \\
\hline Surfacing (at or out of surface and in contact with sides) & 0.484 \\
\hline Floating & 0.465 \\
\hline Climbing & 0.390 \\
\hline Base (remaining at site of release) & -0.630 \\
\hline
\end{tabular}

native and invasive crayfish together. Pairwise comparisons identified significant differences between controls, invasive crayfish, and fish predator cues, but indicated no differences between crayfish groups (see Table IV). The second principal component (eigenvalue $=0.886$ 22 percent of variation) was not significantly affected by predator cue (LME: $F_{3,115}=0.531$, $p=0.472)$. 


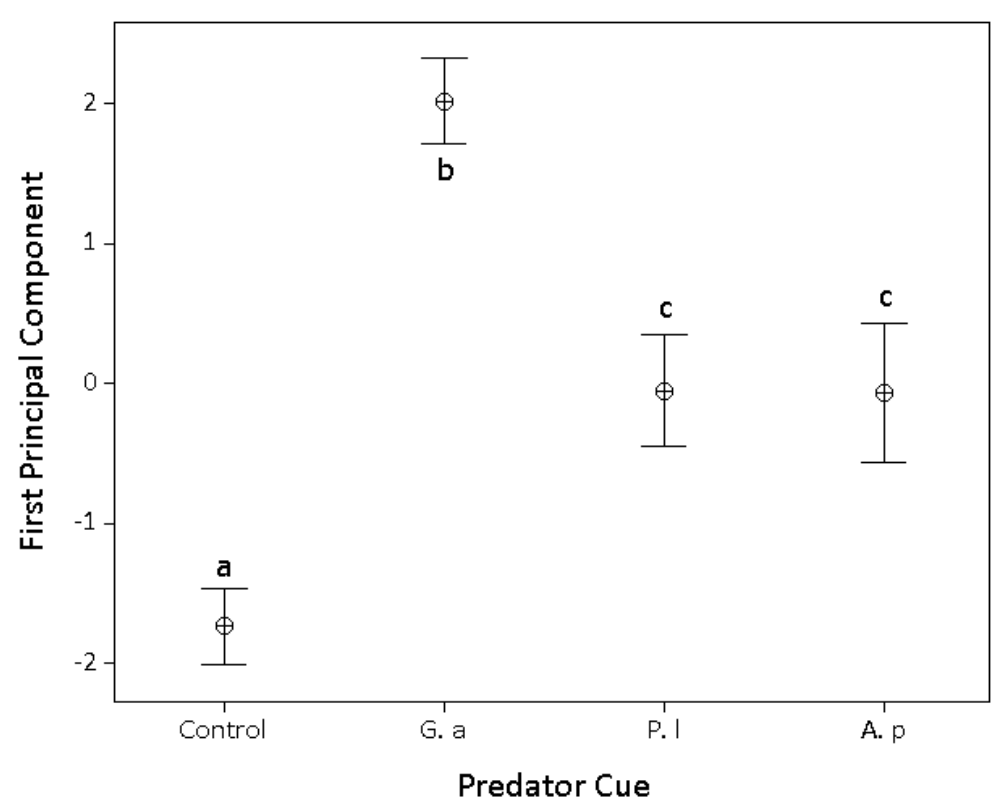

\section{Figure 3}

First principal component from PCA of vertical migration activity in Potamopyrgus jenkinsi between predator cues. "Control" - no predator cue, "Native fish" - Gasterosteus aculeatus, "Non-native crayfish" - Pacifastacus leniusculus, "Native crayfish" Austropotamobius pallipes. Points are means and bars are \pm two standard errors. Different letters indicate significant pairwise differences at Bonferoni adjusted $\alpha=0.008$.

\section{Table IV}

Pairwise comparisons of $P$. jenkinsi vertical migration responses to different predator cues. Degrees of freedom for all pairwise comparisons $=1.57$. ${ }^{*}$ denotes statistical significance relative to a Bonferonniadjusted level of alpha, $\alpha=0.008$.

\begin{tabular}{|l|c|c|c|c|}
\cline { 2 - 5 } \multicolumn{1}{c|}{} & Control & Native fish & Native craytish & Invasive craytish \\
\hline Control & - & $F=501.469$ & $F=72.147$ & $F=79.553$ \\
& & $p<0.001^{*}$ & $p<0.001^{*}$ & $p<0.001^{*}$ \\
\hline Native fish & & - & $F=66.273$ & $F=94.727$ \\
& & & $p<0.001^{*}$ & $p<0.001^{*}$ \\
\hline Native crayfish & & & - & $F=0.006$ \\
& & & & $p=0.938$ \\
\hline Invasive crayfish & & & & - \\
\hline
\end{tabular}

\section{DISCUSSION}

We found that G. pulex responded differently to fish and crayfish predators, which probably reflects the different selective pressures imposed by these predators. In accord with previous studies (Perrot-Minnot et al., 2007), they responded to olfactory cues from native fish by increasing the time spent in the dark. G. aculeatus is a visual predator (Ohguchi, 1978) and is diurnal (Sevenster et al., 1995), and this antipredator behaviour displayed by G. pulex should reduce the likelihood of predation. We found no evidence of a locomotory response to the fish predator, in contrast with other studies that have reported decreased locomotion in response to olfactory fish cues (Dunn et al., 2008; Åbjörnsson et al., 2000). These differences may reflect the selective pressures of the habitat. In our study, G. pulex were sourced from a shallow muddy stream, where habitat features such as a low water depth and dense benthic detritus may reduce the risk of visual detection whilst favoring refuge seeking responses to fish predators. Antipredator responses can be costly (e.g. Daly et al., 2012), affecting reproduction and distribution patterns (e.g. Dunn et al., 2008) and hence there is likely to be strong selection for habitat specific responses that optimize the tradeoff between predator avoidance and other life history costs. 
In contrast with the response to fish, G. pulex showed no change in phototactic behaviour but responded to crayfish by moving further over the 180-second experimental period. This behaviour may reduce the likelihood of predation (Ohman, 1988) by these nocturnal, sit-andwait predators (Gherardi et al., 2001), since darkness is not necessarily a haven from predation by crayfish and yet increased movement during daylight, when crayfish are less likely to be feeding, may well result in reduced predation.

The snail, $P$. jenkinsi, responded to all three predator cues. It showed the greatest movement in response to native fish olfactory cues, displaying more surfacing, climbing, and floating responses than remaining on the base. A lower level of these relocating behaviours occurred in response to the two crayfish predator cues. The difference in magnitude of response elicited between native fish and both crayfish cues may result from the different modes of predation of these predators. Fish feed throughout the water column and snails on all surfaces are susceptible to predation, although those that escape the water column by exiting the water or moving to refuge in habitat complexity may escape, accounting for the elevated activity in response to fish. Crayfish, however, can only feed from the benthos and so snails need only migrate above the level accessible to crayfish chelae to avoid predation. In a simple environment, such as our experimental containers and many natural environments, this corresponds to vertical migration. This observation of vertical migration in response to crayfish predation is in accord with observations in the field (e.g. Lewis, 2001), where snail distribution in North American lakes was negatively spatially correlated with crayfish presence. Turner et al. (2000) and Bernot and Turner (2001) found the snail Physa integra to respond differently to fish and crayfish, but they noted that snails sought shelter in the presence of fish and vertically migrate in the presence of crayfish, whereas shelter was not provided in current study. Our results contrast with studies of Lymnaea, however, who found no response to non-native crayfish (Orr and Lukowiak, 2009; Orr et al., 2009).

G. pulex did not demonstrate different antipredator behaviours in the presence of native relative to invasive predator cues to which the study population was naïve. Similarly, no difference in activity was evident in snail behaviours between native and invasive crayfish cues. Covich et al. (1994) found that two species of snail were unable to differentiate between native and invasive crayfish predators, responding similarly to both $P$. leniusculus and Procambarus acutus. Similar work by Dalesman et al. (2006) shows that naïve snails (Lymnaea stagnalis) respond to olfactory cues from native fish predators with vertical migration, despite having no prior experience of the predator. Our results indicate that both $G$. pulex and $P$. jenkinsi are able to detect invasive crayfish despite a similar lack of prior experience, responding with appropriate antipredator behaviours.

The Predator Recognition Continuum Hypothesis predicts that prey may be more likely to generalise antipredator responses to novel predators where the number of predator species is high (Ferrari et al., 2007). It is interesting that both the snail $P$. jenkinsi and the amphipod G. pulex showed similar responses to the native crayfish with which they are sympatric and the invasive crayfish predator. The number of predatory species in Wyke and Meanwood Becks may be sufficiently high that novel potential predators are responded to in the same manner as known predators as predicted by the Predator Recognition Continuum Hypothesis. This high predator diversity may favour generalised responses to crustacean predators, for example, since innate responses would be unfavourably inflexible. A more parsimonious explanation may be, that kairomones released by the invasive crayfish are sufficiently similar to those of the native crayfish that prey simply respond as they would to native predators.

Ferrari et al. (2007) proposed that selection will favour generalisation of antipredator responses to phylogenetically related prey that are likely to share similar predatory tactics. In addition, related predators are more likely to provide similar cues. The native (A. pallipes) and invasive ( $P$. leniusculus) crayfish belong to the same Family and hence kairomones released by the invasive crayfish may be sufficiently similar to those of the native crayfish that prey respond as they would to native predators. In contrast, Gomez-Mestre and Díaz-Paniagua (2011) found that Rana perezi tadpoles exhibited changed activity in response to native dragon fly (Anax imperator) predators but not to the phylogenetically distant invader the red 
swamp crayfish (Procambarus clarkii). Invasive predators drive changes in biodiversity and community structure through their interactions with native prey species. We have recently reported a higher predatory impact by the invasive signal crayfish than the native whiteclawed crayfish (Haddaway et al., 2012). However, our data do not support the hypothesis that naiveté underlies this increased rate of predation, with such differences more likely to reflect differences in predator behaviour. The innate responses of both amphipod and mollusc prey observed in our study indicate a generalised antipredator response that is likely to be adaptive in the context of invasion by novel crayfish predators.

Although reductions in invert diversity and abundance have been reported following invasion by signal crayfish, our results do not support the hypothesis that prey naiveté is a factor for snails and amphipods. Further work is needed to investigate whether other species of prey, particularly those that are already threatened by existing factors such as habitat degradation, also recognise novel crayfish.

\section{AUTHOR CONTRIBUTIONS}

$\mathrm{NH}$ and $\mathrm{AD}$ conceived and designed the experiments. $\mathrm{NH}$ and DV performed the experiments. $\mathrm{NH}$ analysed the data. $\mathrm{NH}$ and $\mathrm{AD}$ wrote the manuscript; other authors provided editorial advice.

\section{ACKNOWLEDGEMENTS}

The authors thank Leeds City Council and Bradford Metropolitan District Council for granting land access. Thanks to Robert Jones for assistance with laboratory work and Emily Imhoff, Katie Arundell, Aurore Dubuffet, and Paula Rosewarne for help with analysis. This work was funded by a National Environmental Research Council (NERC) CASe partnership with the Environment Agency and a NERC IAA grant.

\section{REFERENCES}

Åbjörnsson K., Dahl J., Nyström P. and Brönmark C., 2000. Influence of predator and dietary chemical cues on the behaviour and shredding efficiency of Gammarus pulex. Aquat. Ecol., 34, 379-387.

Albins M.A. and Hixon M.A., 2013. Worst case scenario: potential long-term effects of invasive predatory lionfish (Pterois volitans) on Atlantic and Caribbean coral-reef communities. Environ. Biol. Fish., 96, 1151-1157.

Auld J.R., Agrawal A.A. and Relyea R.A., 2010. Re-evaluating the costs and limits of adaptive phenotypic plasticity. P. Roy. Soc. B-Biol. Sci., 277, 503-511.

Bernot R.J. and Turner A.M., 2001. Predator identity and trait-mediated indirect effects in a littoral food web. Oecologia, 129, 139-146.

Bethel W.M. and Holmes J.C., 1973. Altered evasive behavior and responses to light in amphipods harboring acanthocephalan cystacanths. J. Parasitol. 59, 945-956.

Brönmark C. and Hansson L.A. (eds.). 2012. Chemical ecology in aquatic systems. Oxford University Press.

Chivers D. and Smith R. 1998. Chemical alarm signalling in aquatic predator-prey systems: a review and prospectus. Ecoscience, 5, 338-352.

Covich A., Crowl T., Alexander Jr J. and Vaughn C., 1994. Predator-avoidance responses in freshwater decapod-gastropod interactions mediated by chemical stimuli. J.N. Am. Benthol. Soc., 13, 283-290.

Dalesman S., Rundle S.D., Coleman R.A. and Cotton P.A., 2006. Cue association and antipredator behaviour in a pulmonate snail, Lymnaea stagnalis. Anim. Behav., 71, 789-797.

Dalesman S., Rundle S.D. and Cotton P.A., 2009. Developmental plasticity compensates for selected low levels of behavioural avoidance in a freshwater snail. Anim. Behav., 78, 987-991. 
Daly D., Higginson A.D., Chen D., Ruxton G.D. and Speed M.P., 2012. Densitydependent investment in costly antipredator defences: an explanation for the weak survival benefit of group living. Ecol. Lett., 15, 576-583.

DeWitt T. and Scheiner S., 2004. Phenotypic plasticity: functional and conceptual approaches. Oxford: Oxford University Press, Oxford.

Dicke M. and Grostal P., 2001. Chemical detection of natural enemies by arthropods: an ecological perspective. Annu. Rev. Ecol. Evol. S., 32, 1-23.

Dunn A.M., Dick J.T.A. and Hatcher M.J., 2008. The less amorous Gammarus: predation risk affects mating decisions in Gammarus duebeni (Amphipoda). Anim. Behav., 76, 1289-1295.

Ferrari M.C.O., Gonzalo A., Messier F. and Chivers D.P., 2007. Generalization of learned predator recognition: an experimental test and framework for future studies. P. Roy. Soc. B-Biol. Sci., 274, 1853.

Gherardi F., Renai B. and Corti C., 2001. Crayfish predation on tadpoles: a comparison between a native (Austropotamobius pallipes) and an alien species (Procambarus clarkii). Bull. Fr. Pêche Piscic., 361, 659-668.

Gomez-Mestre I. and Díaz-Paniagua C., 2011. Invasive predatory crayfish do not trigger inducible defences in tadpoles. P. Roy. Soc. B-Biol. Sci., 278, 3364-3370.

Haddaway N.R., Wilcox R.H., Heptonstall R.E., Griffiths H.M., Mortimer R.J., Christmas M. and Dunn A.M., 2012. Predatory functional response and prey choice identify predation differences between native/invasive and parasitised/unparasitised crayfish. PLoS One 7, e32229.

Harvell C. and Tollrian R. 1999. Why inducible defenses? In: Tollrian R., Harvell C. (eds.), The ecology and evolution of inducible defences. Princeton University Press, Princeton, 3-9.

Harvey G.L., Moorhouse T.P., Clifford N.J., Henshaw A.J., Johnson M.F., Macdonald D.W., Reid I. and Rice S.P., 2011. Evaluating the role of invasive aquatic species as drivers of fine sediment-related river management problems: the case of the signal crayfish (Pacifastacus leniusculus). Prog. Phys. Geog., 35, 517-533.

Jackson M.C., Jones T., Milligan M., Sheath D., Taylor J., Ellis A., England J. and Grey J., 2014. Niche differentiation among invasive crayfish and their impacts on ecosystem structure and functioning. Freshwater Biol., 59, 1123-1135.

Lewis D.B. 2001. Trade-offs between growth and survival: responses of freshwater snails to predacious crayfish. Ecology, 82, 758-765.

McGeoch M.A., Butchart S.H.M., Spear D., Marais E., Kleynhans E.J., Symes A., Chanson J., Hoffmann M., 2010. Global indicators of biological invasion: species numbers, biodiversity impact and policy responses. Divers. and Distrib., 16, 95-108.

Mery F., Burns J.G. 2010. Behavioural plasticity: an interaction between evolution and experience. Evol. Ecol., 24, 571-583.

Nyström P. and Åbjörnsson K., 2000. Effects of fish chemical cues on the interactions between tadpoles and crayfish. Oikos 88, 181-190.

Ohguchi O., 1978. Experiments on the selection against colour oddity of water fleas by three-spined sticklebacks. Z. Tierphysiol. Tierer 47, 254-267.

Ohman M.D., 1988. Behavioral responses of zooplankton to predation. B. Mar. Sci. 43, 530-550.

Orr M. and Lukowiak K. 2009. Sympatric predator detection alters cutaneous respiration in Lymnaea. J. Exp. Biol., 212, 2237-2247.

Orr M.V., Hittel K. and Lukowiak K. 2009. Different strokes for different folks': geographically isolated strains of Lymnaea stagnalis only respond to sympatric predators and have different memory forming capabilities. J. Exp. Biol., 212, 2237-2247.

Paterson R.A., Pritchard D.W., Dick J.T., Alexander M.E., Hatcher M.J. and Dunn A.M. 2013. Predator cue studies reveal strong trait-mediated effects in communities despite variation in experimental designs. Anim. Behav., 86, 1301-1313.

Perrot-Minnot M.J., Kaldonski N. and Cézilly F. 2007. Increased susceptibility to predation and altered anti-predator behaviour in an acanthocephalan-infected amphipod. Int. J. Parasitol., 37, 645-651.

Pinheiro J.C. and Bates D.M., 2000. Mixed-effects models in S and S-plus. Springer.

R Development Core Team, 2005. R: A Language and Environment for Statistical Computing. Vienna, Austria: R Development Core Team. 
Reed T.E., Waples R.S., Schindler D.E., Hard J.J. and Kinnison M.T. 2010. Phenotypic plasticity and population viability: the importance of environmental predictability. P. Roy. Soc. B-Biol. Sci., 277, 3391-400.

Rohlf F.J., 1997. TPSDig. State University of New York, New York.

Sevenster P., Bruijn E.F.D. and Huisman J.J., 1995. Temporal structure in stickleback behaviour. Behaviour, 132, 1267-1284.

Sin A. and McCarthy T., 2002. Prey responses to pulses of risk and safety: testing the risk allocation hypothesis. Anim. Behav., 63, 437-443.

Simberloff D., 2011. How common are invasion-induced ecosystem impacts? Biol. Invasions, 13, $1255-1268$.

Trussell G.C. and Nicklin M.O., 2002. Cue sensitivity, inducible defence, and trade-offs in a marine snail. Ecology, 83, 1635-1647.

Turner A., 2008. Predator diet and prey behaviour: freshwater snails discriminate among closely related prey in a predator's diet. Anim. Behav., 76, 1211-1217.

Turner A., Bernot R. and Boes C., 2000. Chemical cues modify species interactions: the ecological consequences of predator avoidance by freshwater snails. Oikos, 88, 148-158.

Turner A.M., 1996. Freshwater snails alter habitat use in response to predation. Anim. Behav., 51, 747-756.

Vitousek P.M., D'Antonio C.M., Loope L.L. and Westbrooks R., 1996. Biological invasions as global environmental change. Am. Sci., 84, 468-478. 